\title{
MITI clears new path for Japan's universities
}

Tokyo. As reforms sweep through Japan's higher education system, the bureaucratic walls that have made it difficult for the country's universities to receive government research funds from agencies other than the Ministry of Education, Science and Culture (Monbusho) are crumbling.

This month, the New Energy and Industrial Technology Organization (NEDO), which is affiliated to the Ministry of International Trade and Industry (MITI), expects to receive hundreds of applications from university researchers for 100 large project grants, each worth 50-200 million yen (US\$0.6-2.3 million), to develop the 'seeds' of new technology.

It is the first time that a ministry other than Monbusho has been permitted to offer substantial research funds to universities without interference from the education ministry. The NEDO scheme also marks the beginning of a new era, in which large sums of government money are allocated to universities considered to be carrying out top-rate research.

The NEDO funds are included in a supplementary budget approved by the government in May that was intended to mitigate the effects of the Kobe earthquake, but also includes substantial funds for science.

National research institutes as well as universities are eligible to apply for the project funds, which will be awarded in September after review by a committee drawn from universities, national institutes and the private sector. Research fields to be covered include biotechnology, new materials, electronics and information technology, medical, energy and environmental technology.

NEDO's "epoch-making" scheme came as a "surprise", says Hiroshi Saito, a professor at the Tsukuba Advanced Research Alliance (TARA). This is a new organization set up last year by Tsukuba University to encourage joint research between the university, national research institutes and private companies in Tsukuba science city north-west of Tokyo (Nature 369, 268; 1994).

Saito says the project, as well as other related government policy changes, marks an "excellent opportunity for universities to make themselves more open to society and

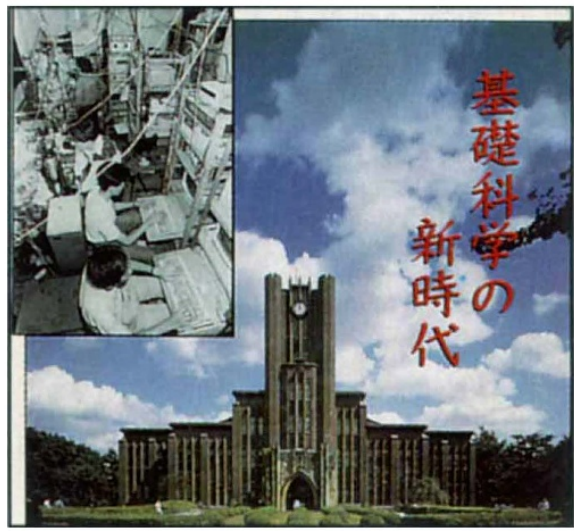

'Japan: time for change': Tokyo University, from special issue of Nature, October 1992.

to expand research by getting a lot of support from outside".

NEDO is not the first non-Monbusho organization to provide large research funds to university researchers. But it is the first to secure the support of the education ministry, which has up to now maintained a bureaucratic stranglehold on university research.

The Science and Technology Agency (STA) has for many years run the Exploratory Research for Advanced Technology (ERATO) programme that provides large project funds to teams of researchers, often headed by university professors.

But such project leaders have to set up an off-campus project office, and cannot officially carry out ERATO research in the university. Indeed, it is widely rumoured that university researchers who accept ERATO funds risk being cut off from funding from Monbusho.

Hiroyuki Kishi, deputy director of MITI's Office for Industrial Science and Technology Frontier Programme in the Agency of
Industrial, Science and Technology, which oversees the new NEDO scheme, says MITI has had frequent contact with Monbusho over the new programme, and that "no special problems" have arisen.

Kishi says that university researchers who win project funding will be free to buy equipment and to use existing university facilities. They will even be able to hire postdoctoral fellows through NEDO.

The NEDO scheme is one of a number of new programmes through which large sums of government money are being allocated to specific universities. This contrasts with Monbusho's traditional approach of providing very small amounts of research funding to all university teaching staff, regardless of what research - if any - they do.

In the current fiscal year the education ministry will provide about 6 billion yen $(\$ 70$ million) of extra money to selected university-related institutes, as well as a handful of chosen teams of university researchers, in an effort to create centres of excellence (see Nature 371, 188; 1994).

Monbusho has also won 2 billion yen in the supplementary budget for a scheme to be run by the Japan Society for Promotion of Science. This will provide 20 project grants of comparable size to NEDO's to support joint university/industry research.

Saito of TARA says that such moves demonstrate that Monbusho "has begun to endeavour to return the research results of universities to industry". The days of the "ivory tower", he suggests, are now over.

But sceptics say much will depend on how university researchers are selected for funding. In the past, a few powerful professors, with strong links to Monbusho, have tended to choose where the largest grants go.

Critics, including those awarded large Monbusho grants, argue that only with a truly open system of competitive peer review - perhaps involving foreign researchers -will a real revolution take place in Japan's university research. David Swinbanks

\section{Report claims that United States is producing too many PhDs}

San Francisco. US universities are awarding 25 per cent more doctorates in science and engineering than the economy can absorb, according to researchers at the Rand Corporation and Stanford University's Institute for Higher Education.

"There are institutions producing doctorates whose decision to stop doing so would probably not be noticed by the world," says William Massy, director of the institute, and principal investigator in a new study of postgraduate training. He says that in fields where those universities are not strong, they ought to go out of the business.
Together with Charles Goldman of Rand, Massy analysed 13 science and engineering fields at 210 universities, as well as at 1,000 educational institutions that employ doctoral graduates. They found that, on average, 200 new PhDs in each field fail to find employment related to their degree qualifications every year.

Massy says admission policies to doctoral courses have little relation to the potential job market, but correlate more closely with a particular department's needs for teaching and research assistants.

The report follows on the heels of an analysis by the National Academy of
Sciences that came up with similar results, but drew very different conclusions. The NAS report found more than half of new $\mathrm{PhD}$ graduates find work in non-academic settings. But its authors suggested that employment outside academic institutions does not necessarily represent a misuse of the doctoral programme.

Massy disagrees. He says society needs to take a hard look at the cost-benefit equation of employing doctorates in jobs that do not require such rigorous training. "When you consider the social cost of training a PhD, I don't think it pays out," he says.

Sally Lehrman 